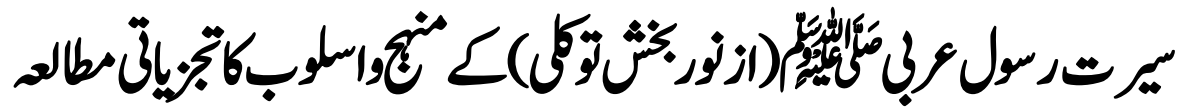

\section{An Analytical Study of Method \& Style of Seerat Rasool-e-Arabi}

Muhammad Shoaib

M.Phil Scholar, the University of Faisalabad, Faisalabad.

Muhammad Mudassar Shafique

Visiting Faculty of Islamic Studies, NUML, Multan.

\section{KEYWOR D S}

Sacred role (Seerat)

Methodology

Noor Bakhsh Tawakli

Literate personage

(Seerat nigar)

\section{A T E S}

\begin{tabular}{ll}
\hline Received & $30-07-2021$ \\
Accepted & $06-12-2021$ \\
Published & $21-12-2021$
\end{tabular}

Q R C O D E

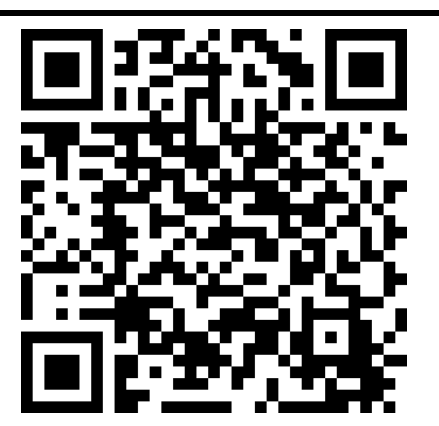

\section{A B S T R A C T}

The topic of 'Sacred role (Seerat)' with the affinity of the Rasool (saw) having significance, status and vast acceptance is undoubtedly beyond expression. If we make analysis of a religious literature, we find most of its part consisting on such topics that are directly affiliated with the silent features of the personality of the Rasool (saw). In storehouse of knowledge and architecture of the world 'Art of Sacred role' has attained its prominent supremacy. The beginning of this artwas based on the details of Ghazwat in Islambut with the passage of time, it was enlarged in such a way that a great piece of literary work on 'Sacred role' has been pin pointed in sub-continent. Many literate of persona put forth their pens on this topic out of whom Noor Bakhsh Tawakli is also the most famous name who wrote a with title of "Seerat Rasool-e-Arabi" on the personality of Rasool. The expression of the affection and following of the Rasool (saw) by Noor Bakhsh Tawakli is expressed by the leaves of this book. He is best known for his popular for this book which has its own status in this field. He wrote the book in the era during which the western civilization had strangled the youth of that time. Materialism was in its climax. A great piece of strife was being made to disintegrate the true bond of affection and following of the Rasool (saw) but the profundity of learning, recognition of knowledge, strict eye on the present condition of that time and the salient factors of love of the Rasool (saw) were quite dominant in this book. The leaves of which were enriched with the florescence of love and affection of Rasool(saw).

DOI: https://doi.org/10.54064/negotiations.v1i3.28

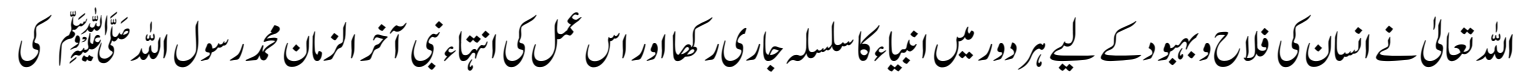

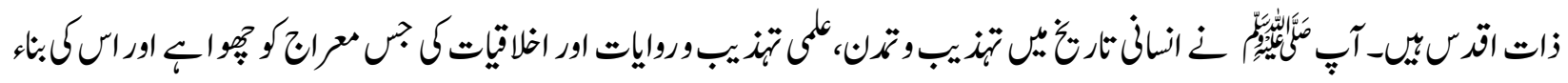

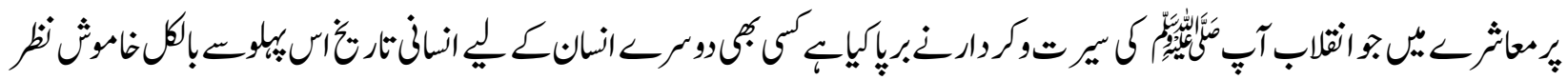




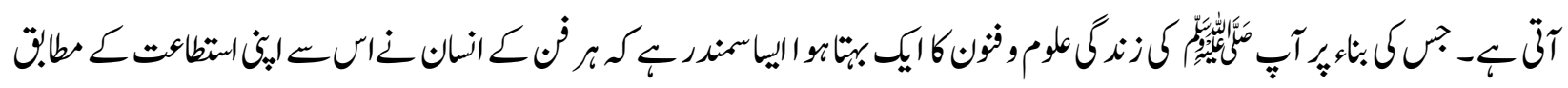

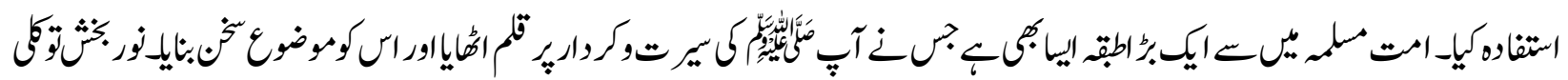

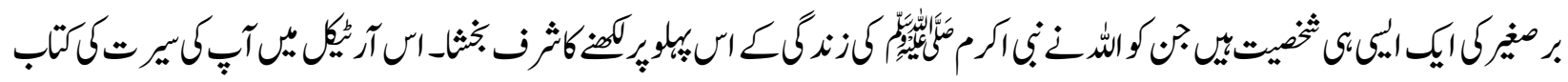

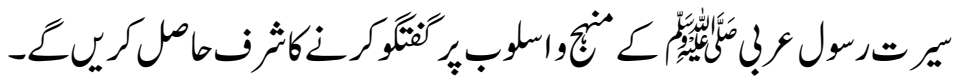

مابقتحثيقات كاباءة:

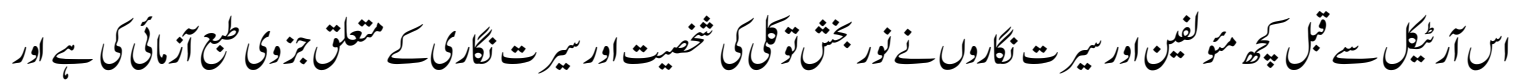

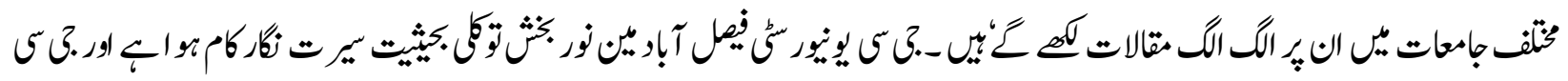

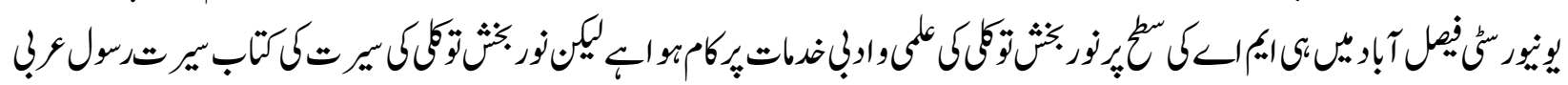

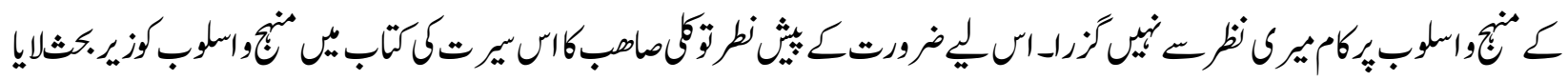

$$
\begin{aligned}
& 4
\end{aligned}
$$

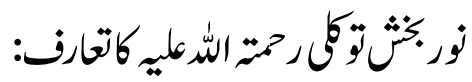

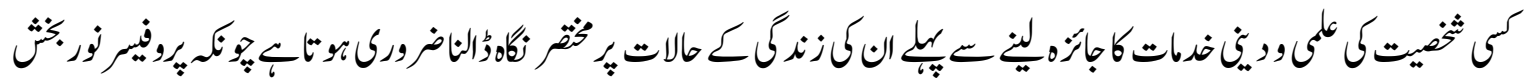

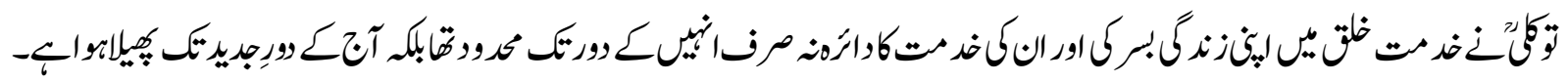

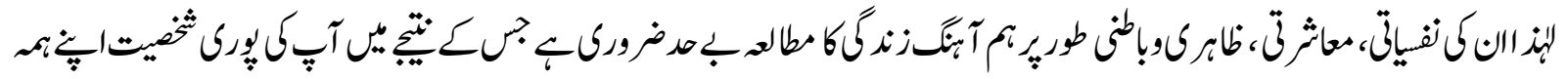

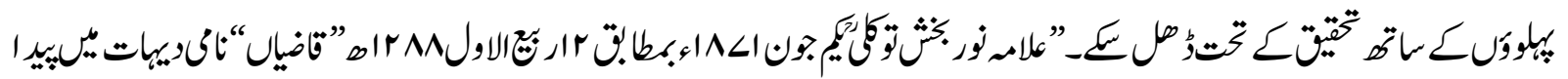

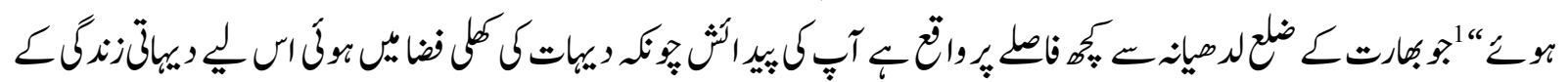

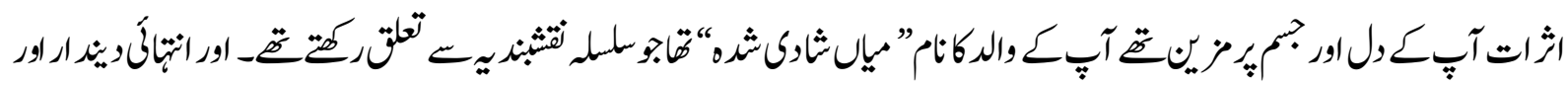

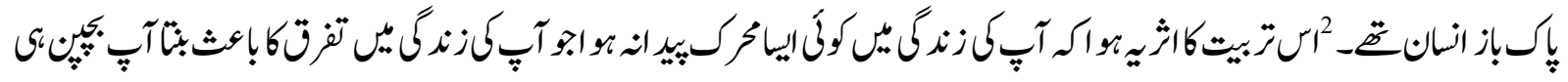

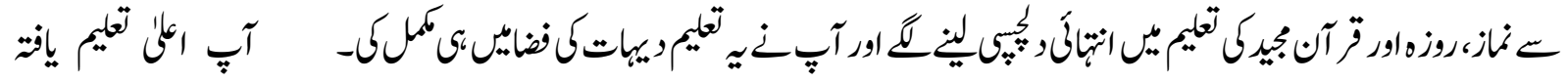

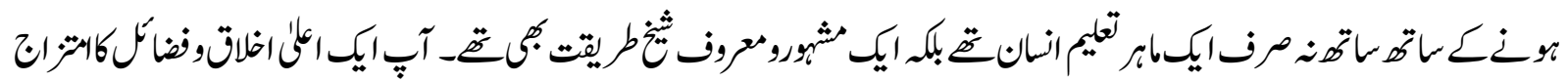

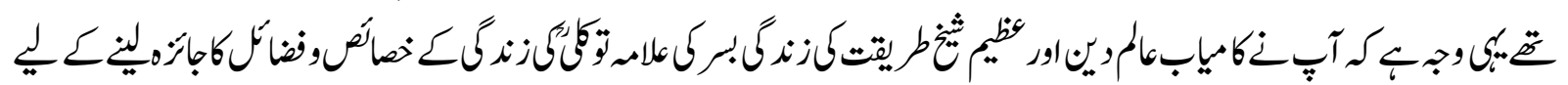

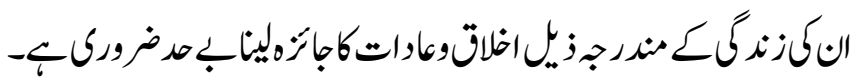

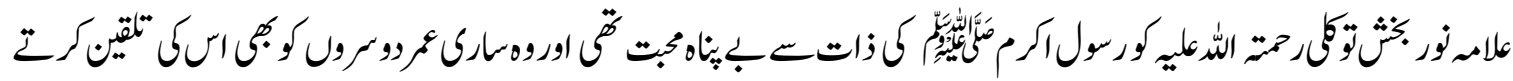

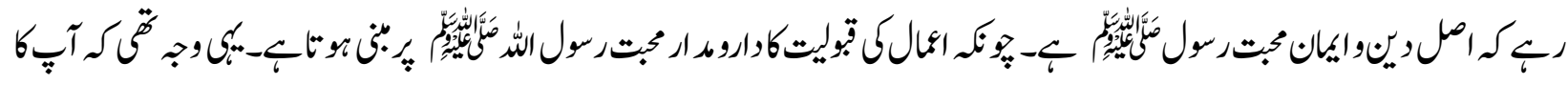

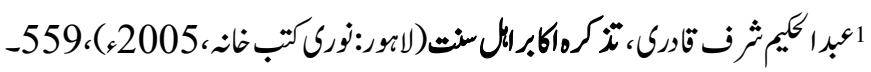

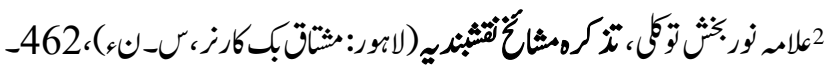




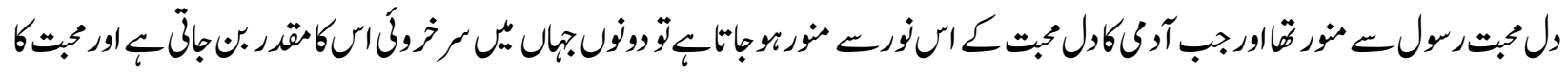

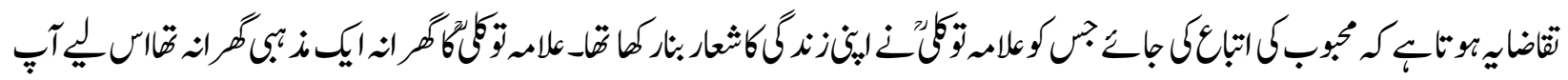

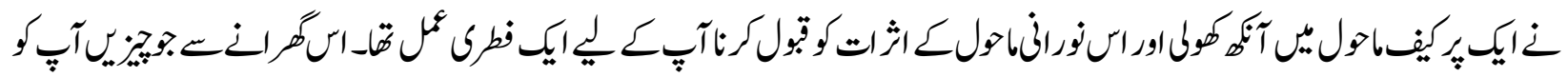

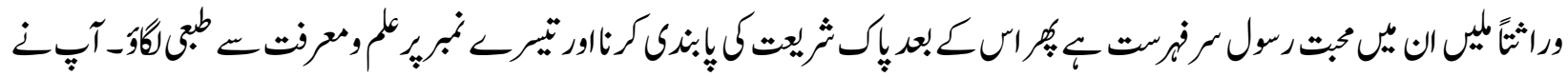

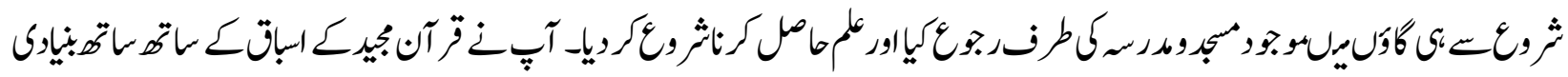

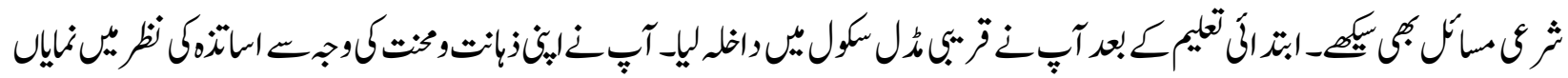

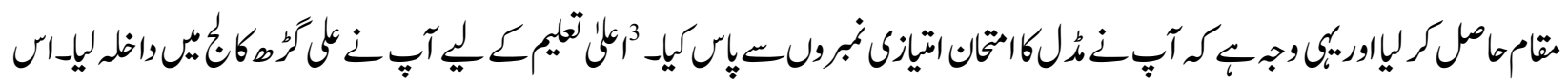

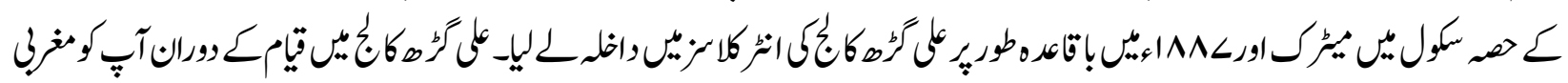

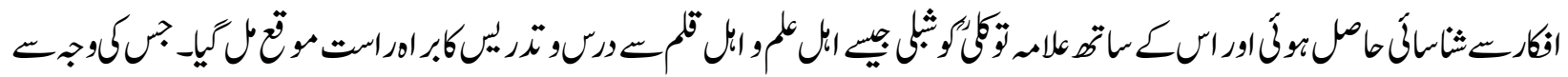

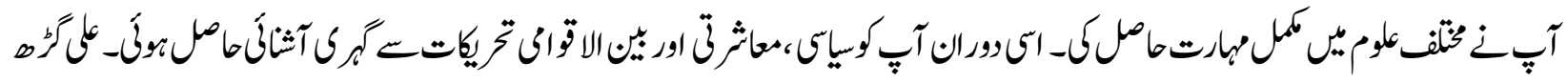

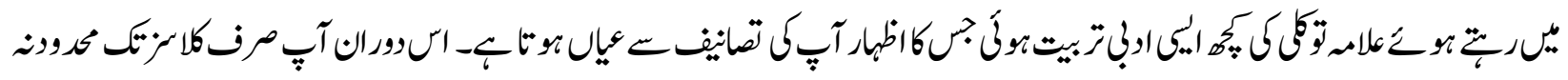

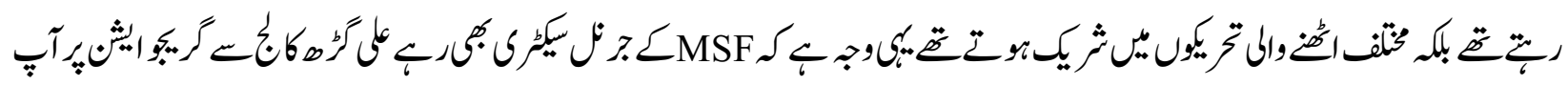

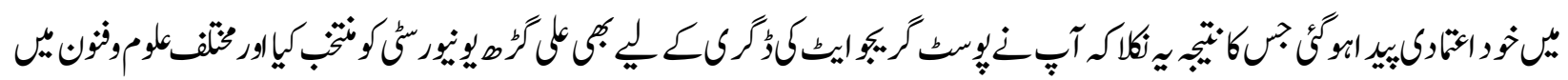
${ }^{4}-36060$

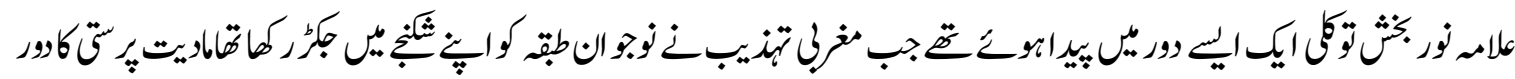

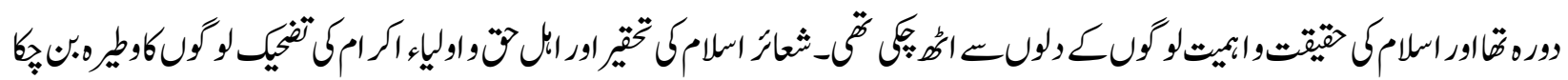

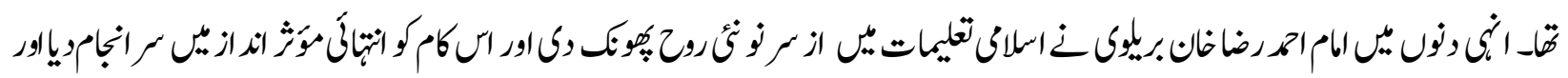

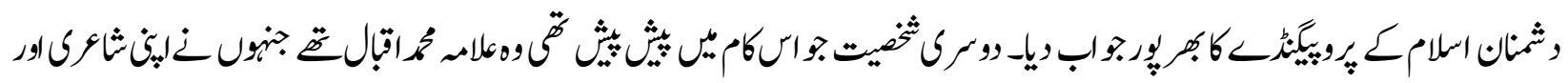

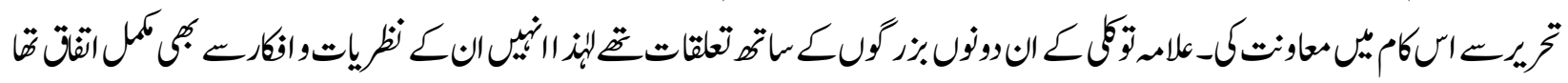

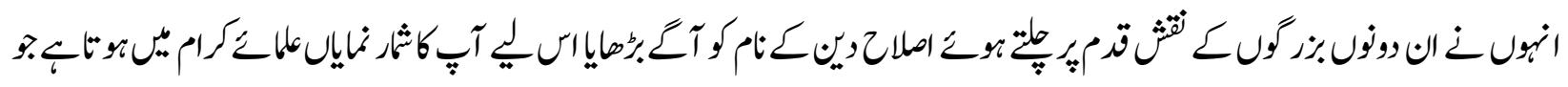

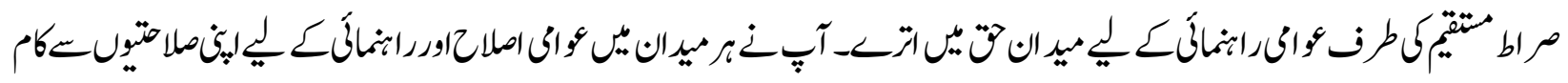

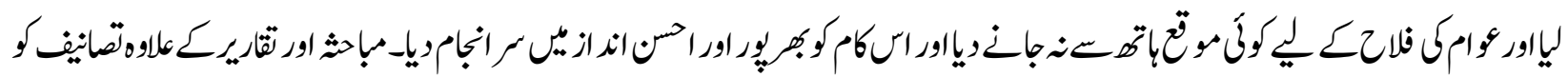

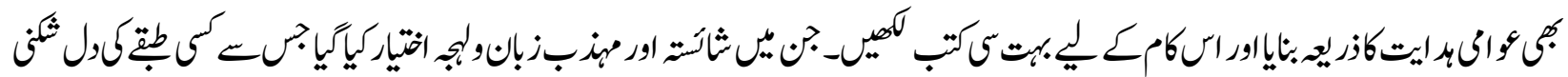

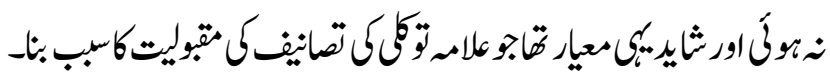

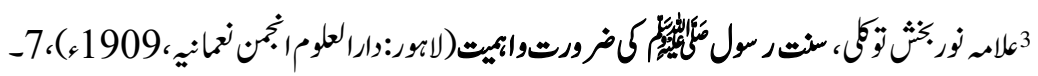

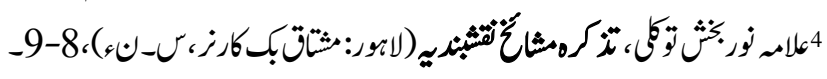




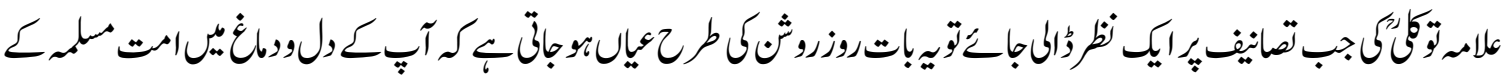

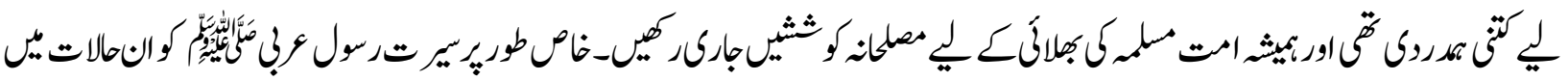

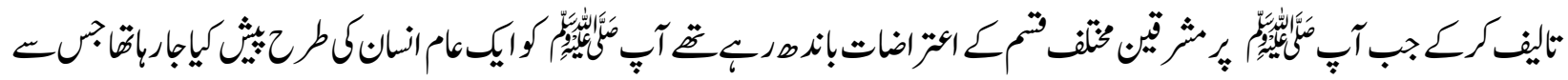

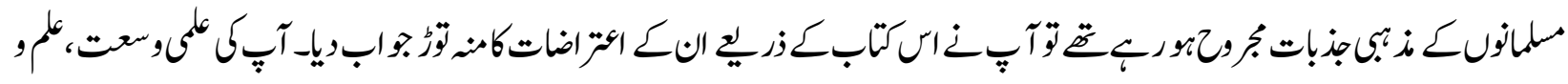

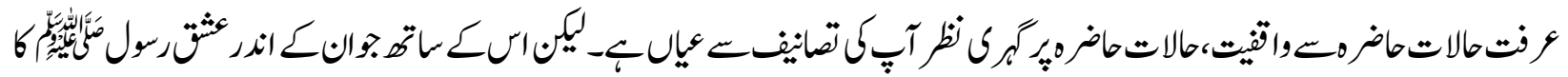

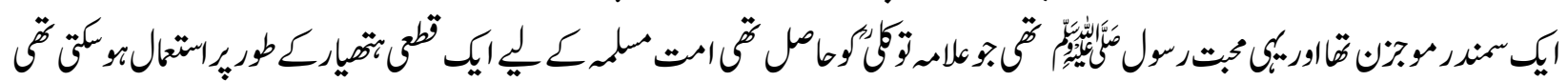

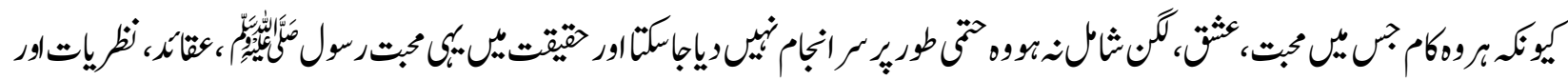

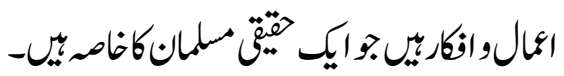

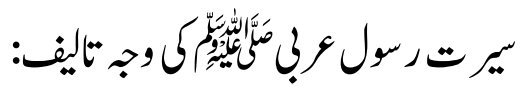

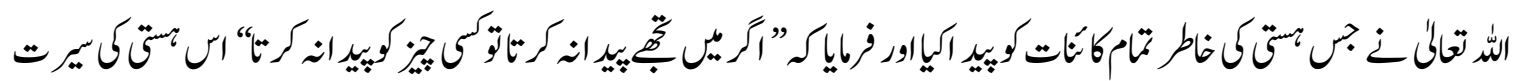

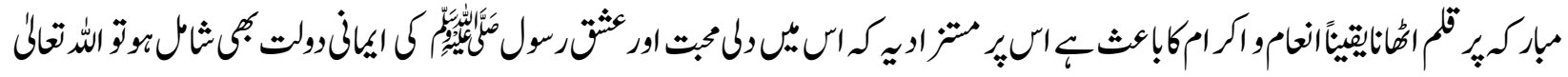

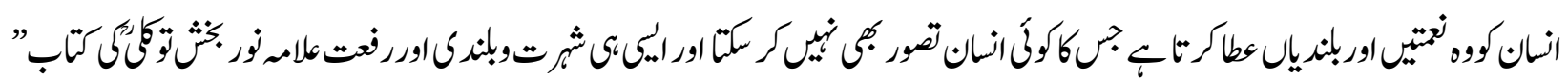

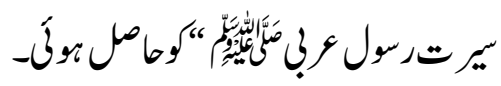

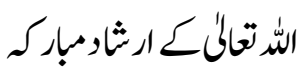

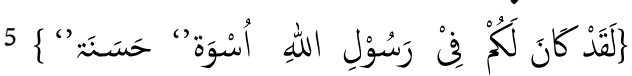

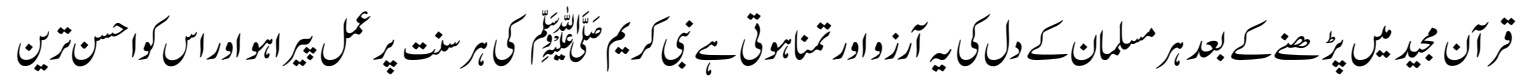

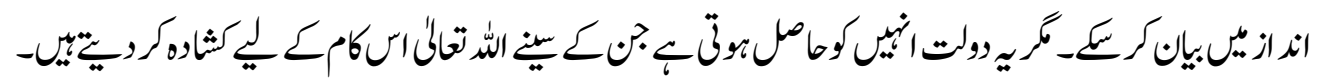

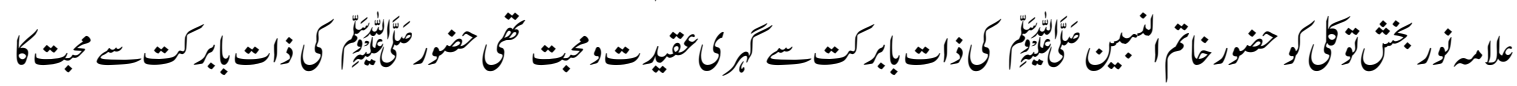

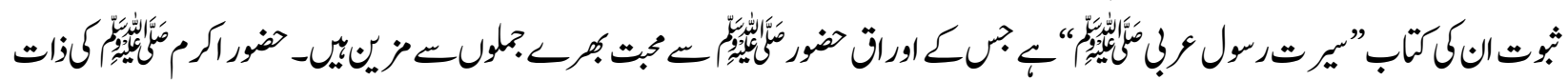

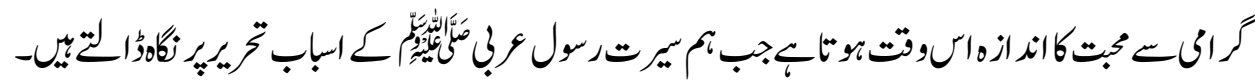

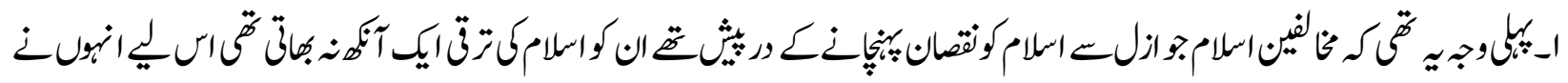

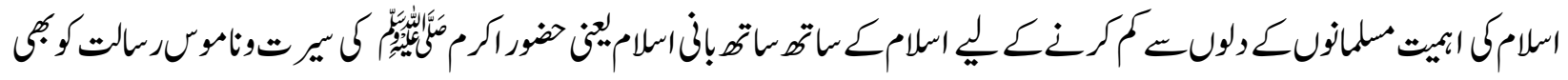

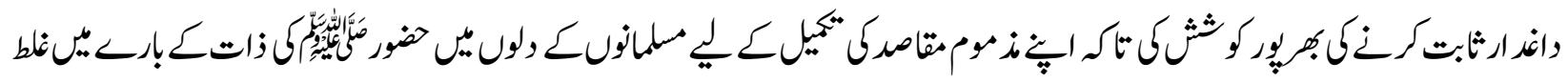

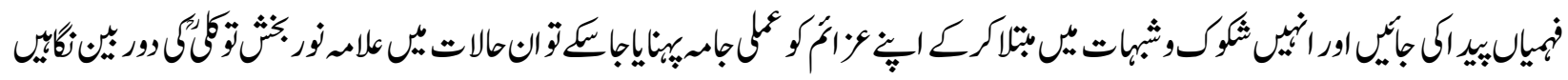

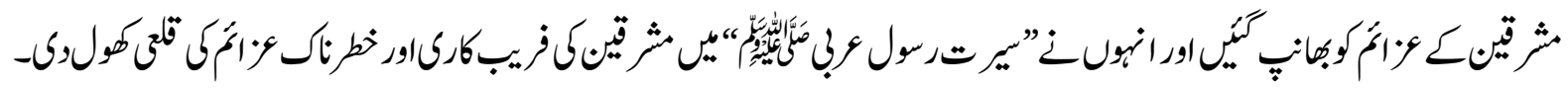




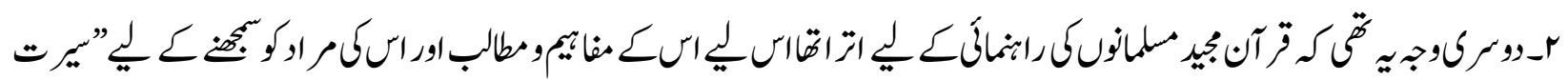

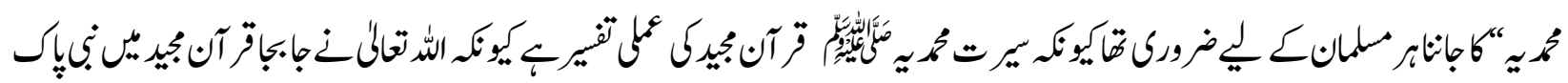

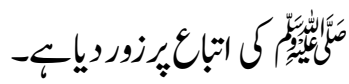

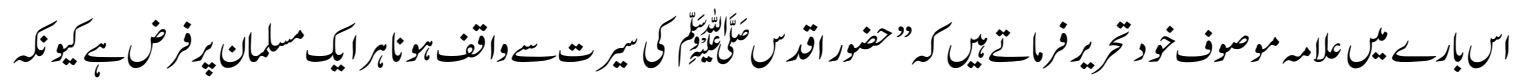

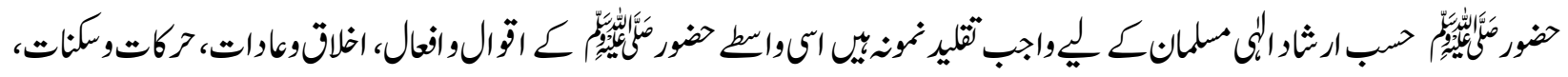

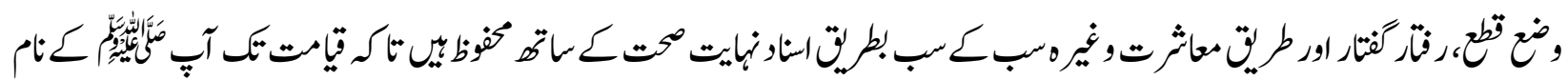

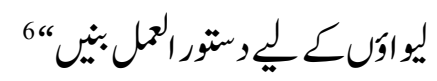

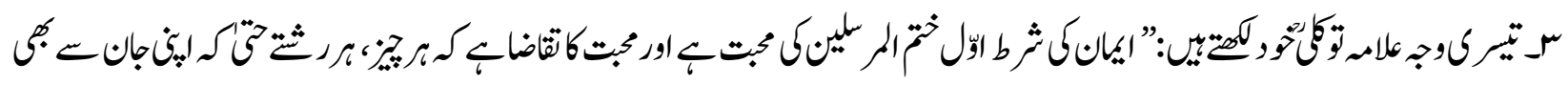

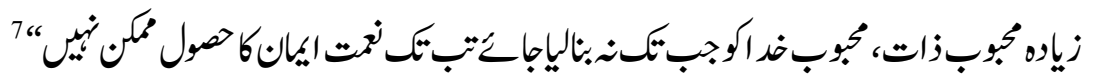

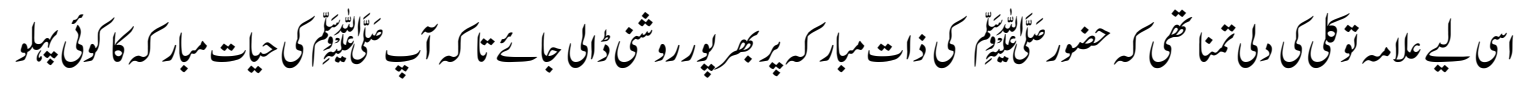

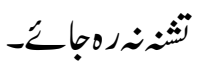

rrr

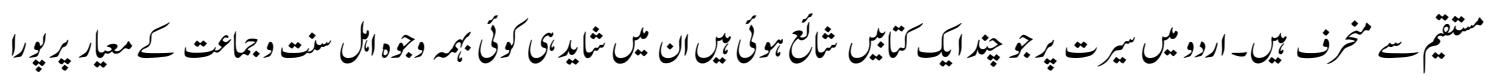

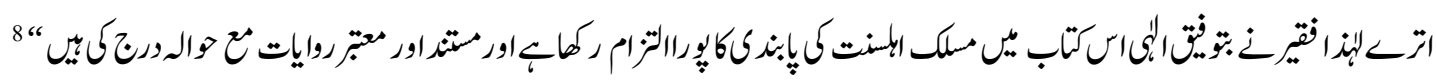

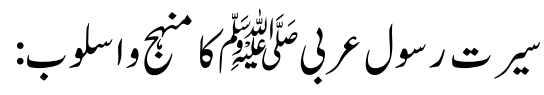

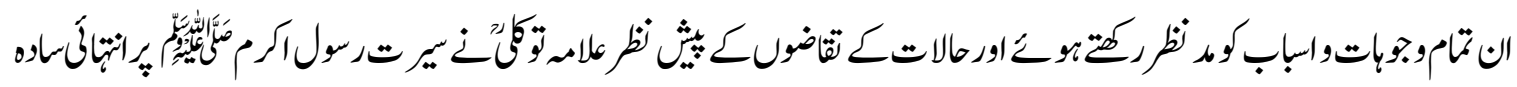

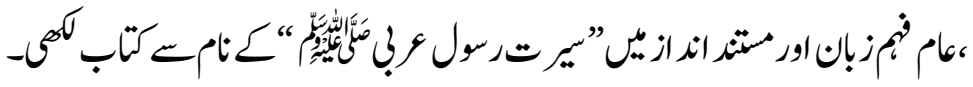

$$
\begin{aligned}
& \text { تردئيان }
\end{aligned}
$$

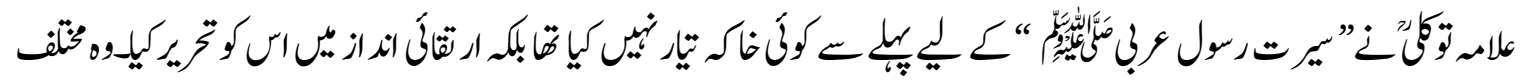

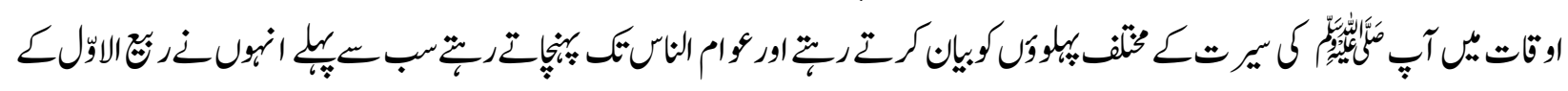

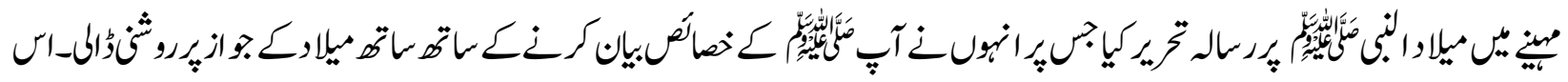

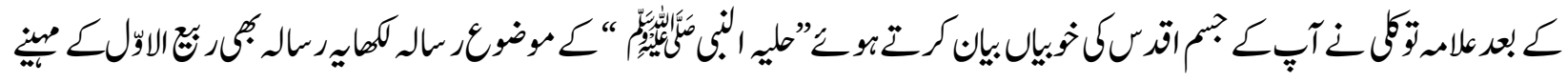

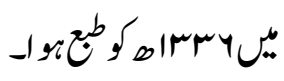

6 


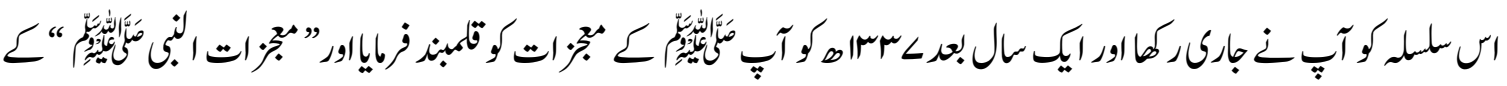

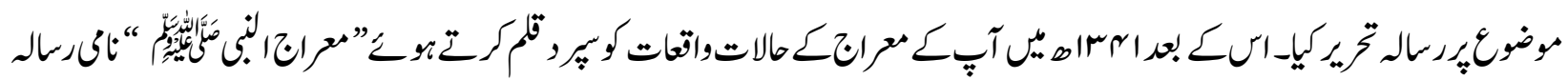

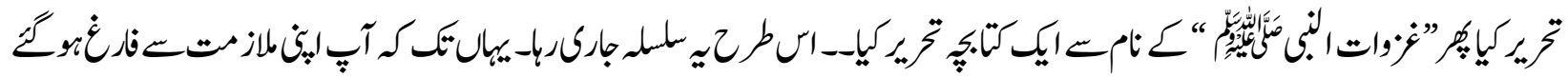

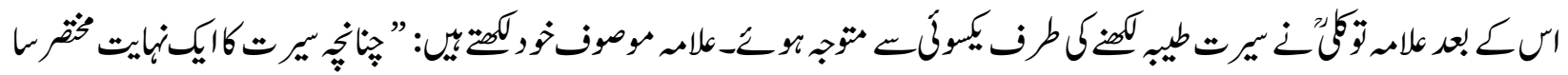

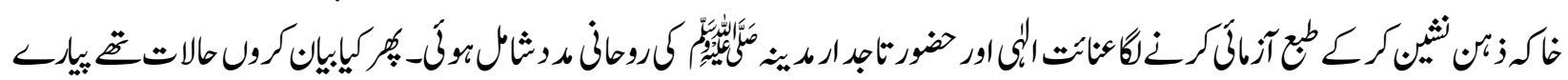

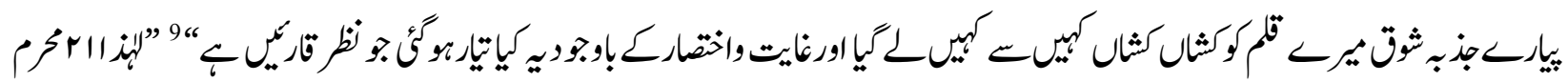

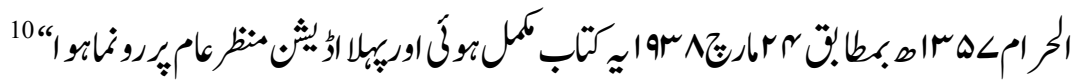

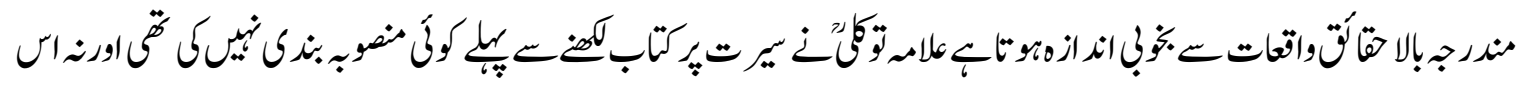

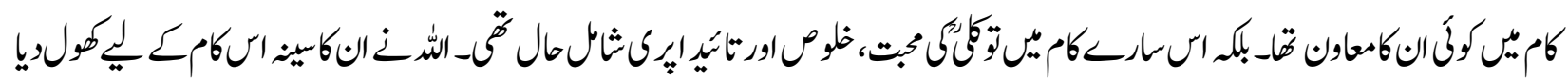

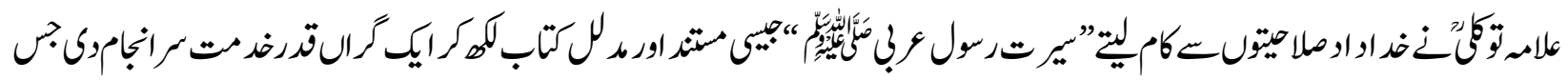

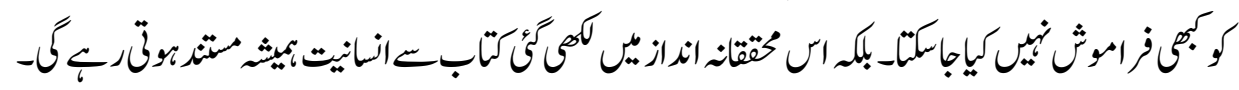

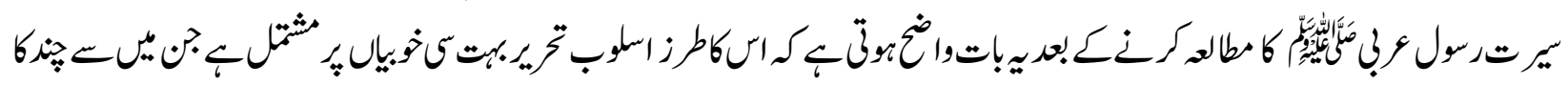

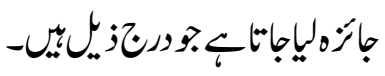

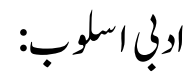

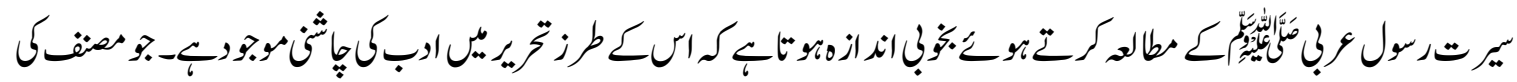

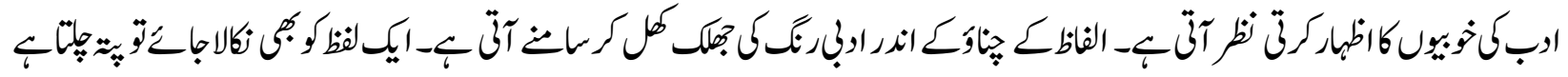

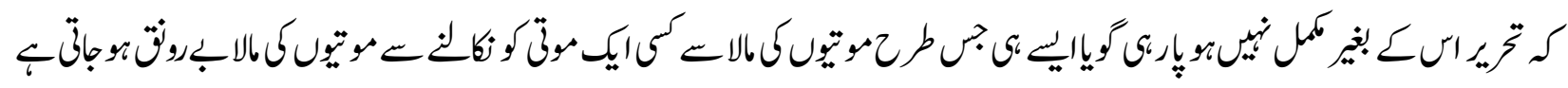

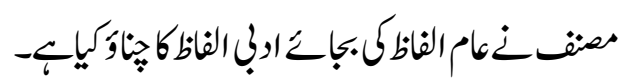

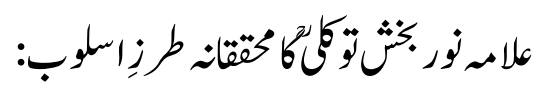

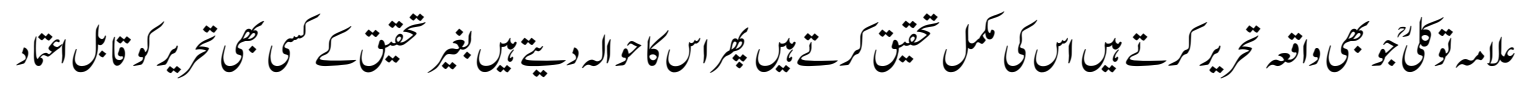

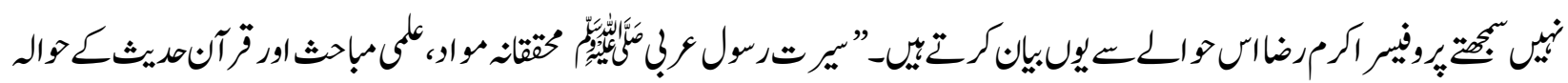

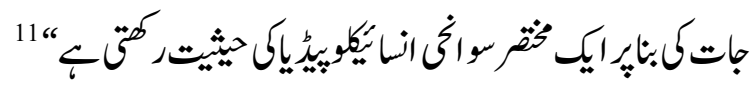




$$
\text { عام نم طرزاسوب: }
$$

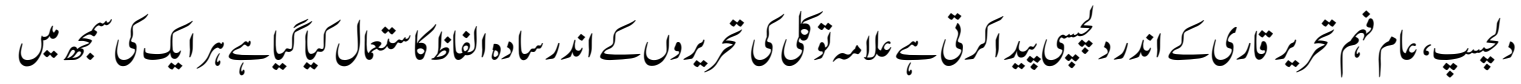

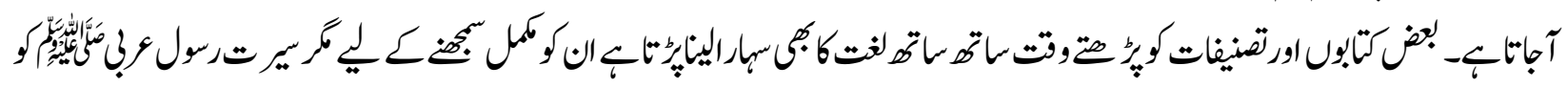

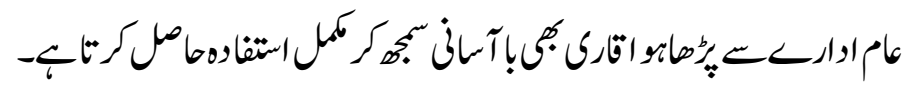

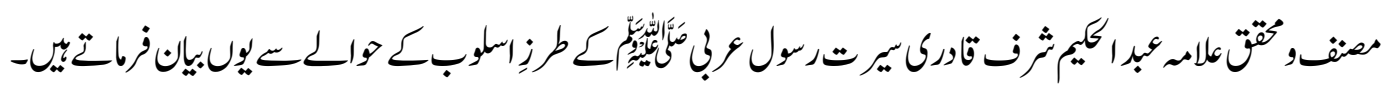

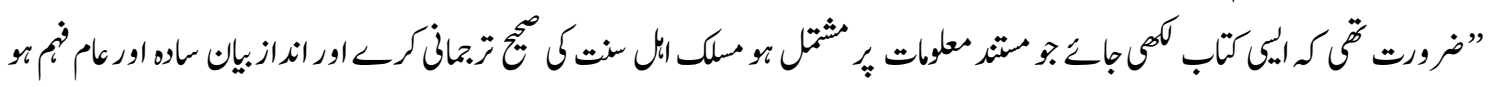

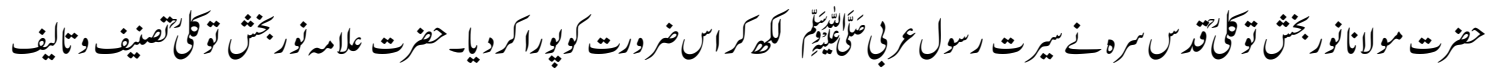

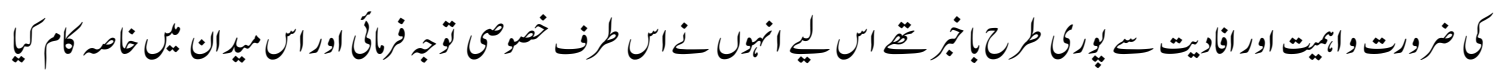

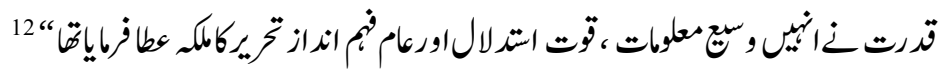

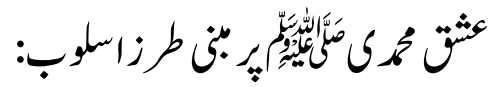

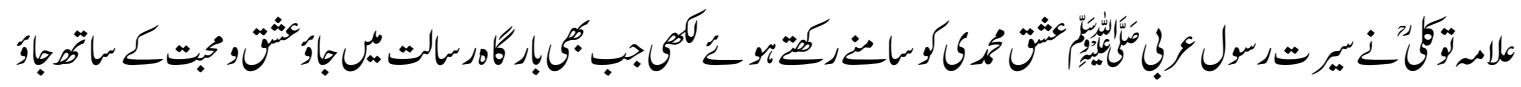

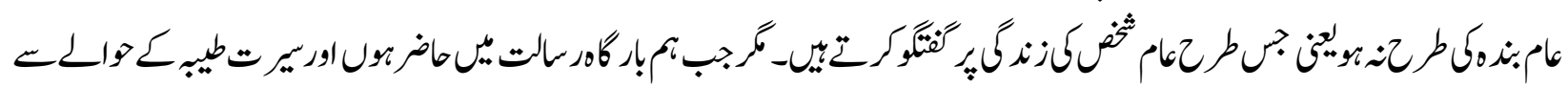

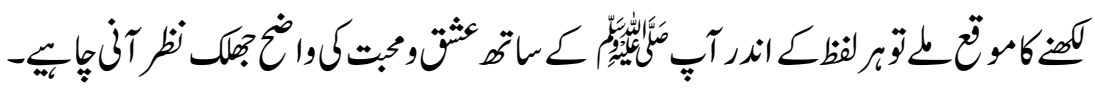

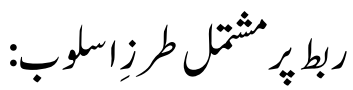

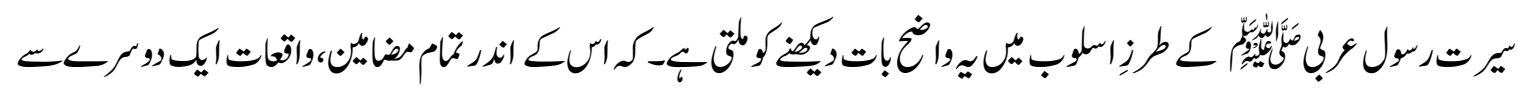

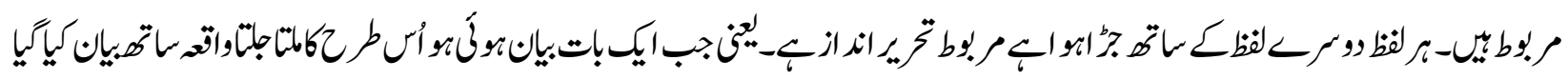

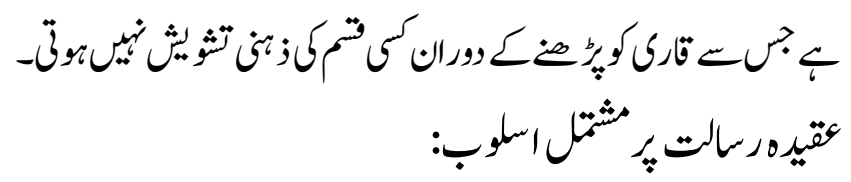

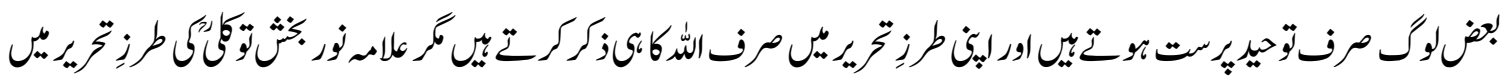

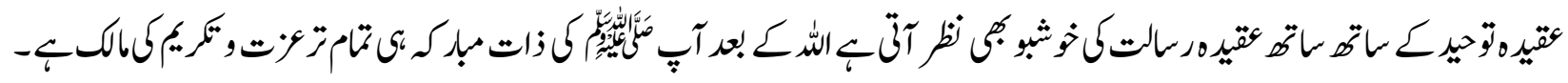

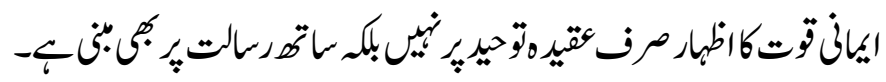

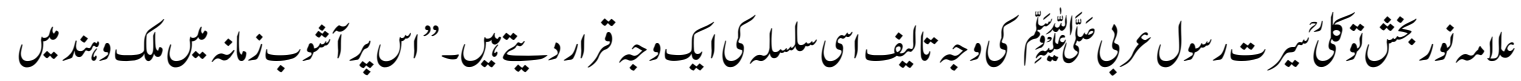

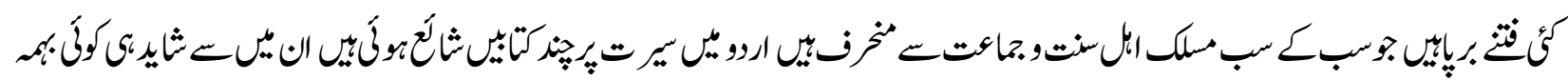

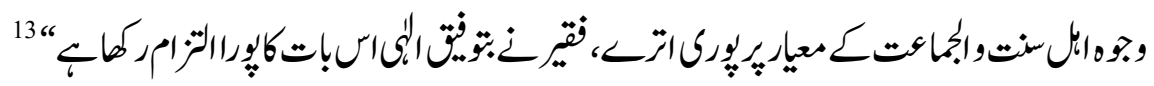

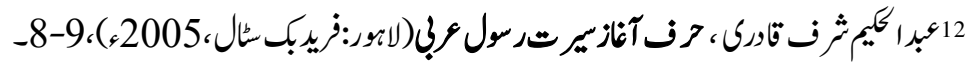

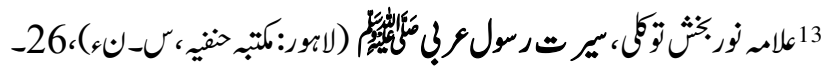




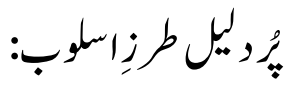

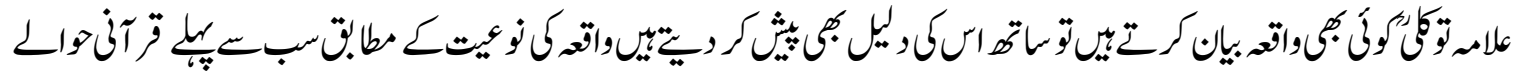

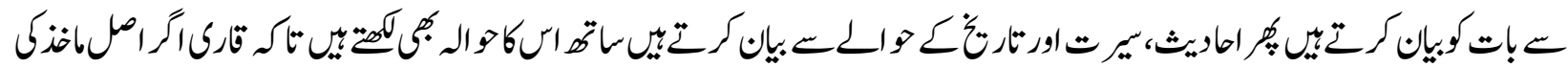

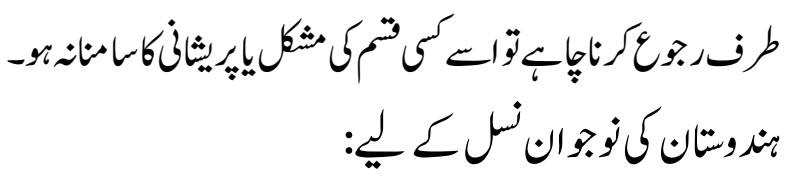

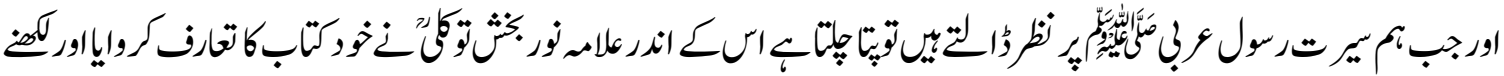

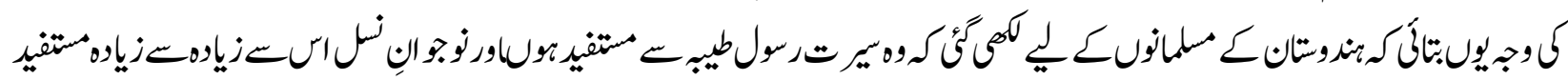

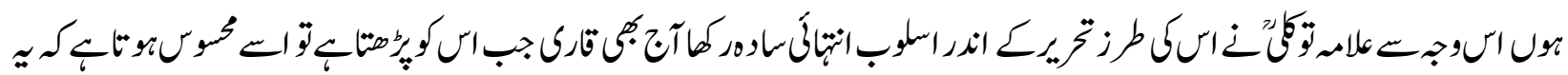

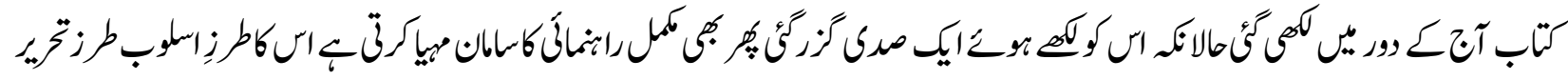

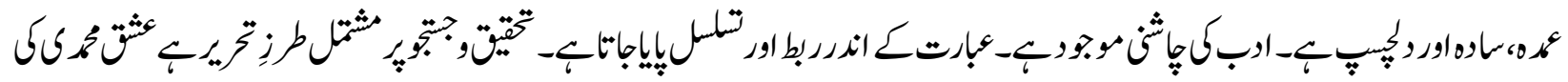

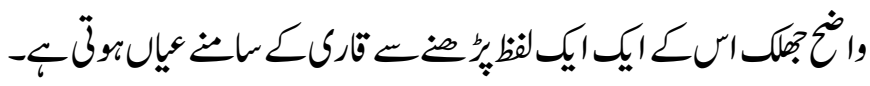

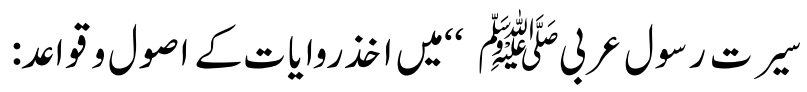

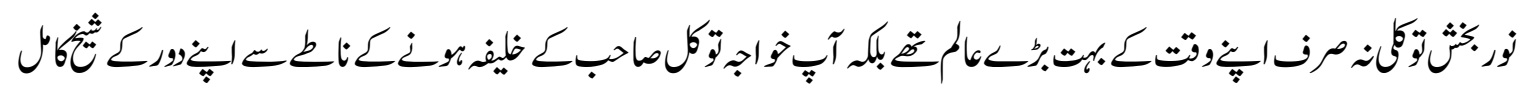

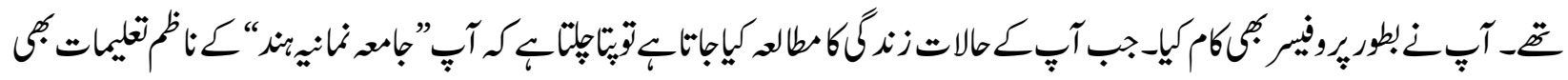

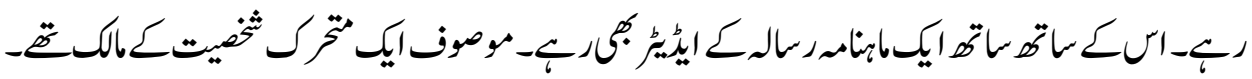

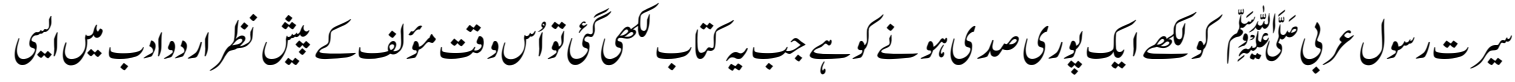

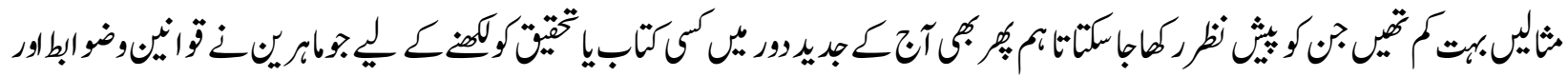

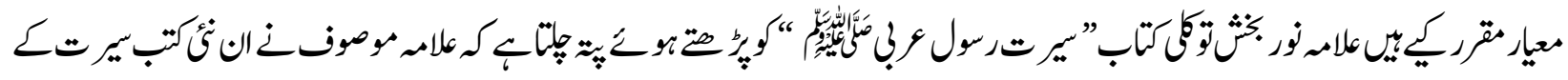

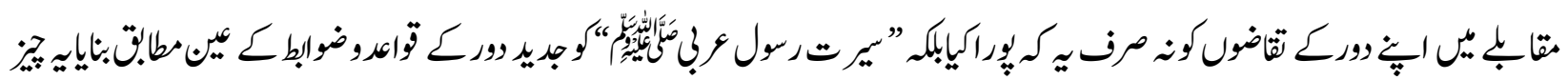

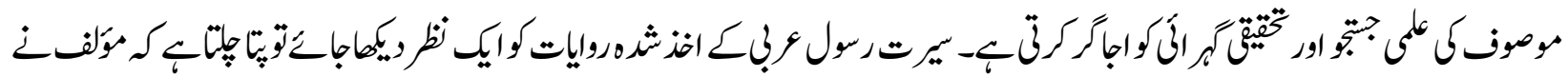

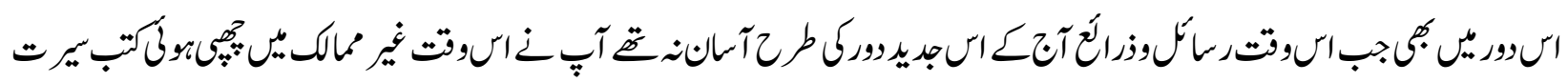

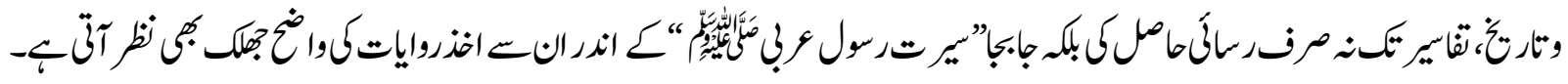

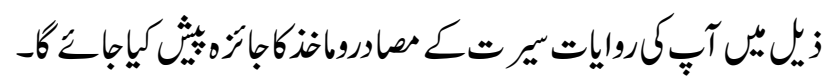

ق آن بجي:

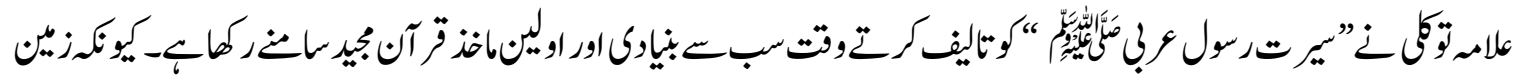

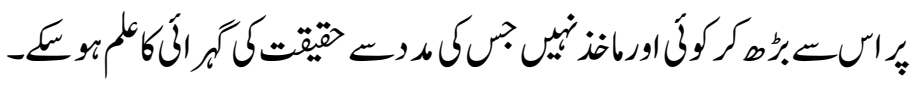




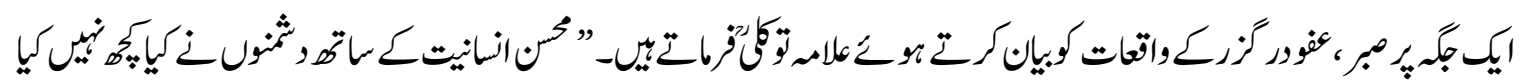

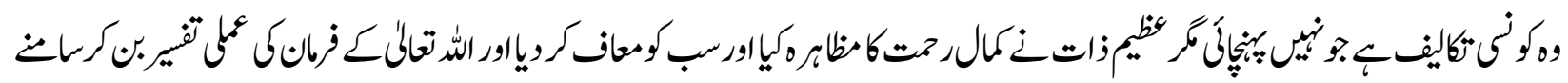

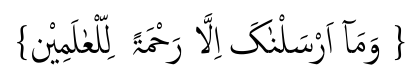

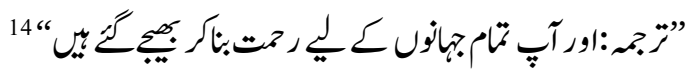

$$
\begin{aligned}
& \text { متجركتب حيث كعروايات كواخذكرن: }
\end{aligned}
$$

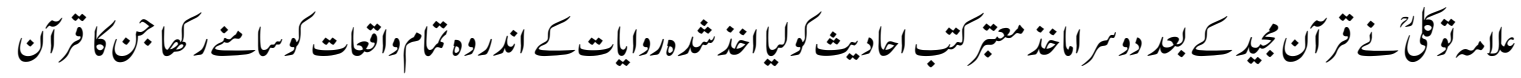

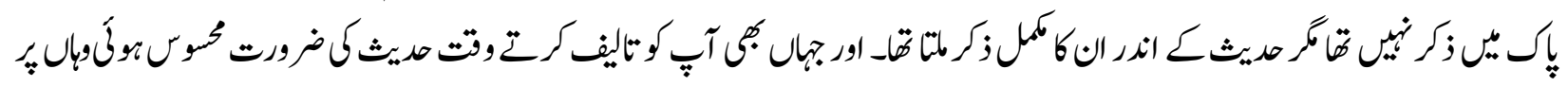

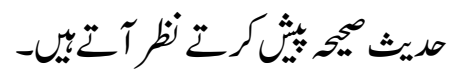

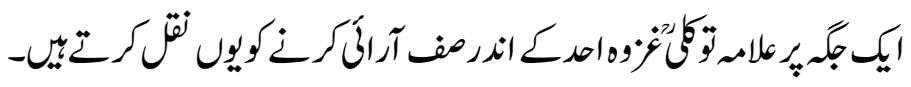

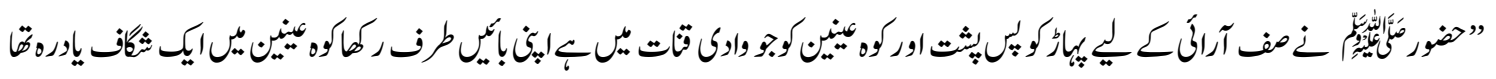

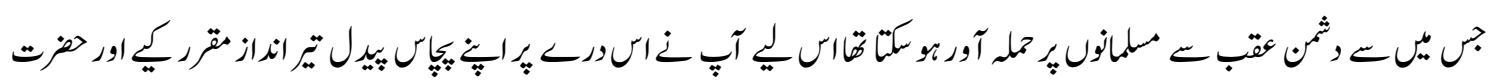

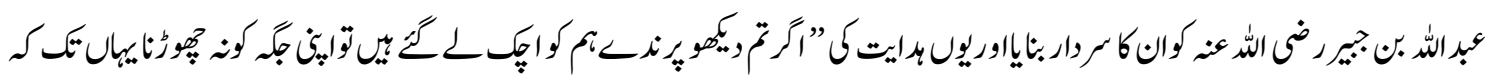

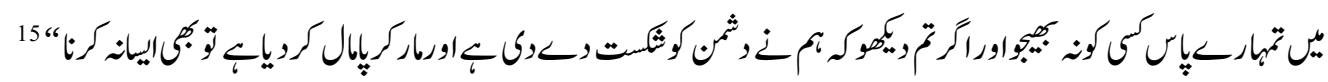

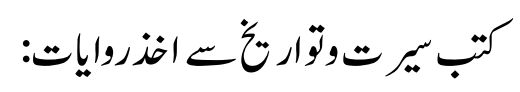

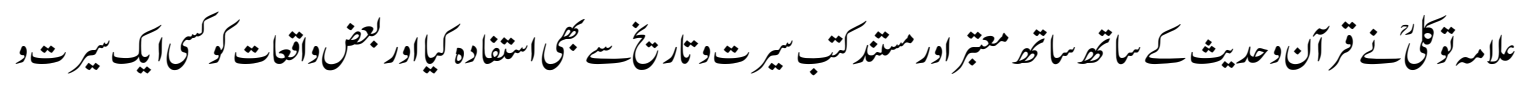

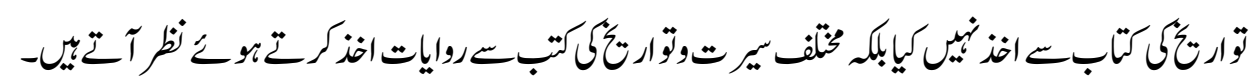

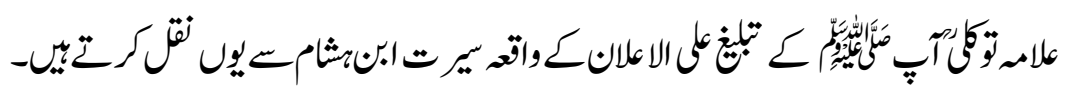

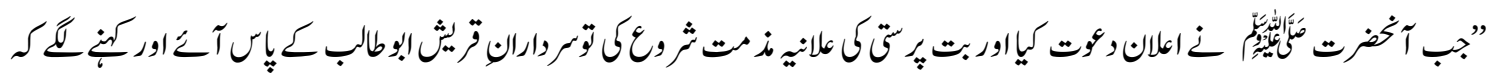

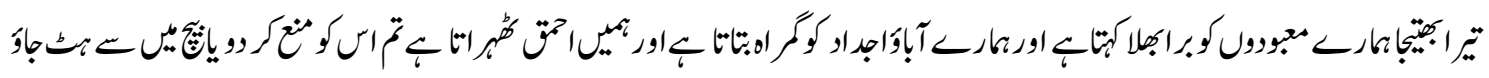

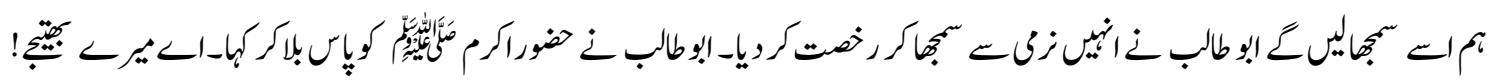

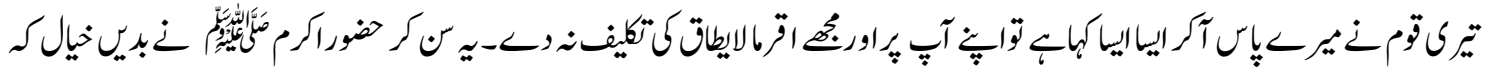

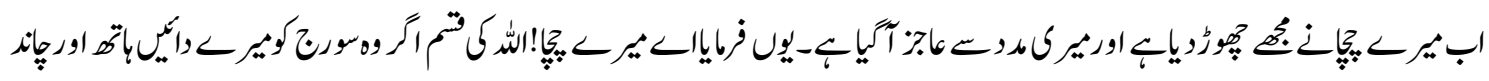

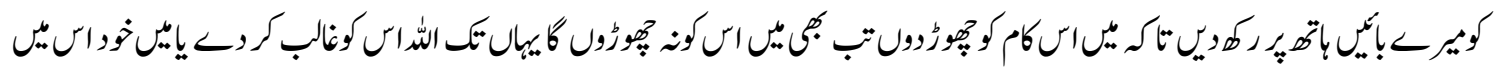

16 بلإك 16

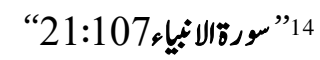

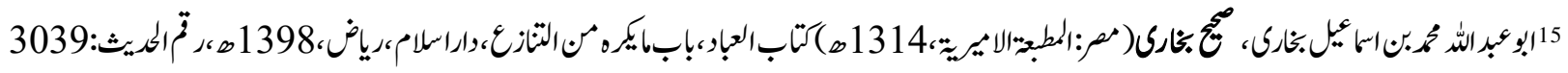

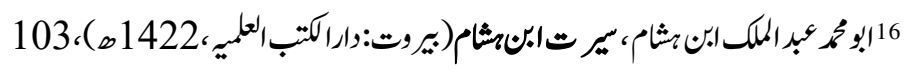




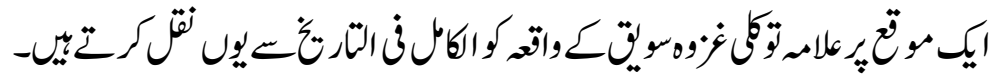

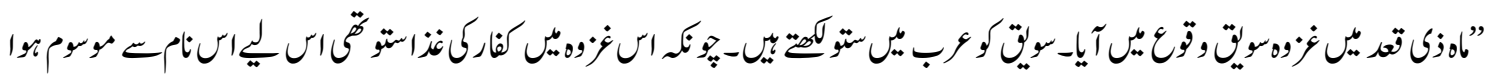

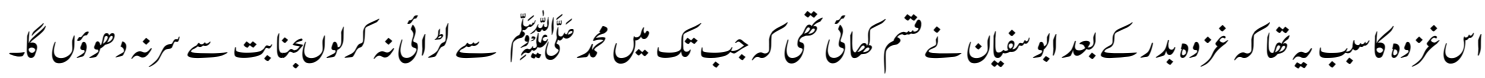

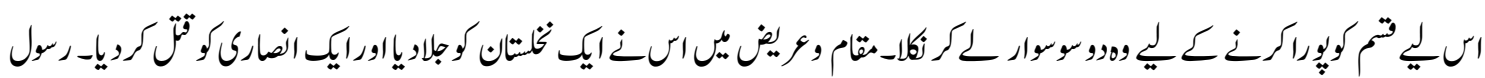

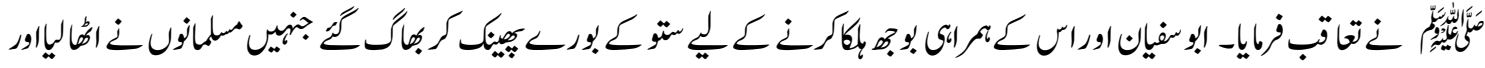

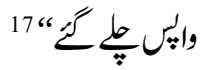

$$
\text { قصيرهبرده بيف ع اشعاركارتتعال: }
$$

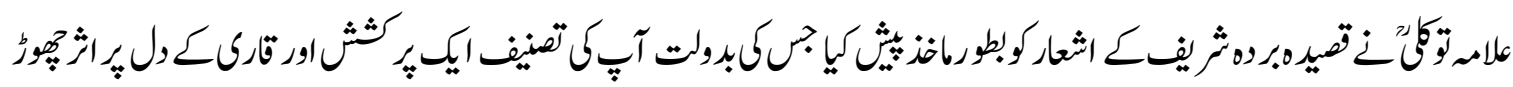

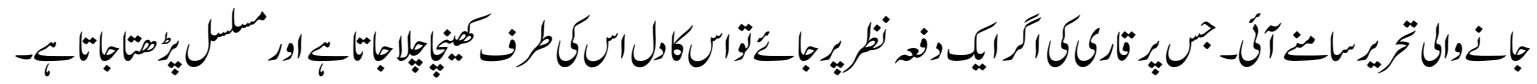

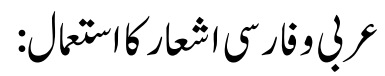

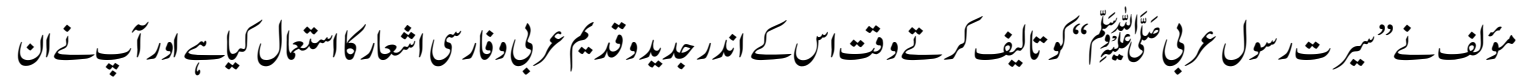

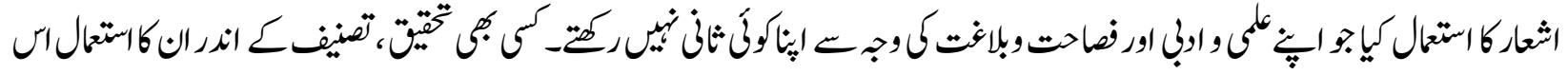

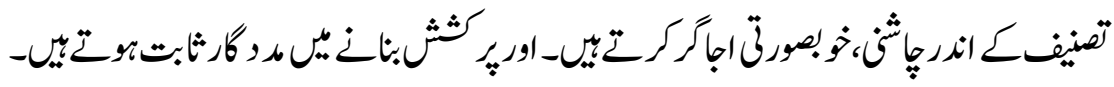

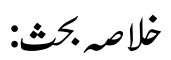

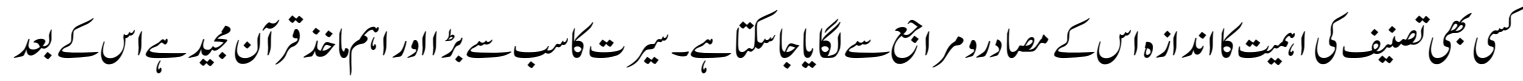

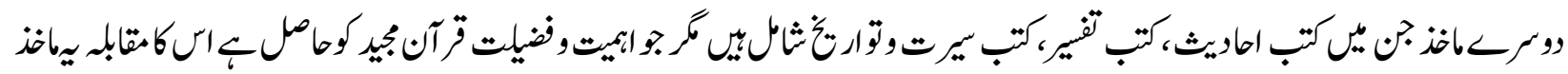

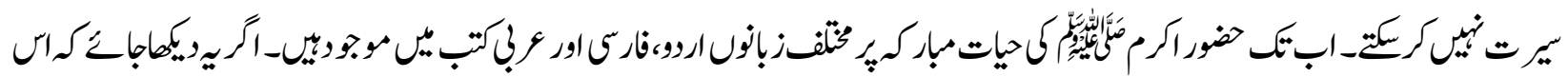

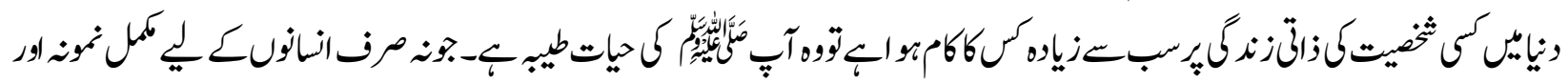

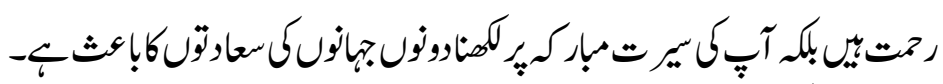

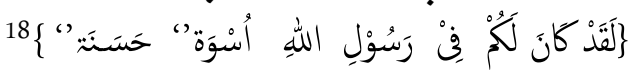

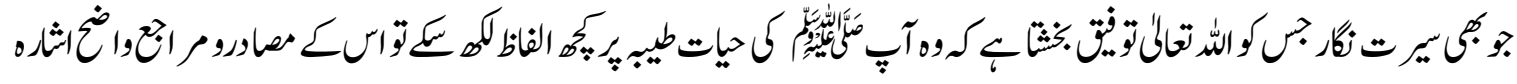

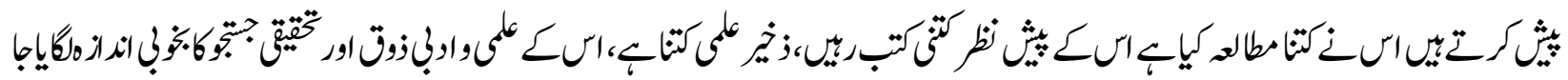

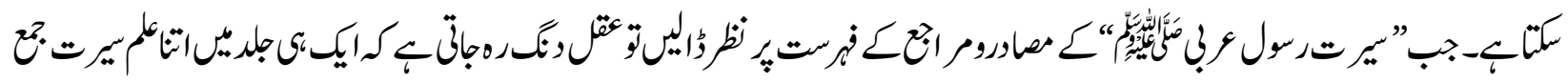

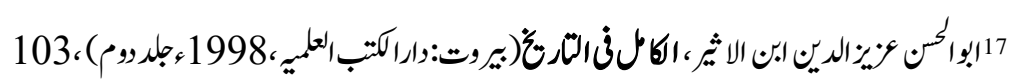

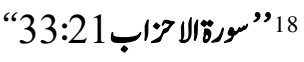




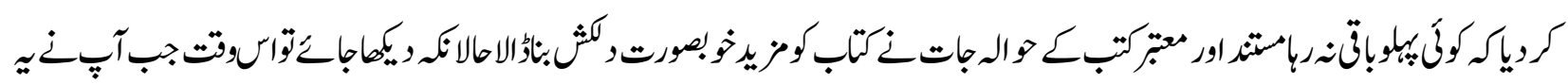

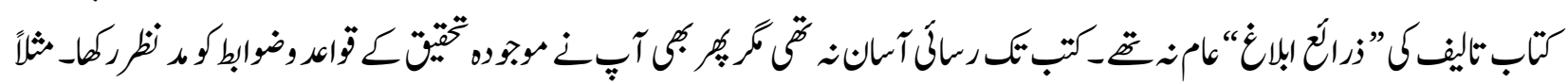

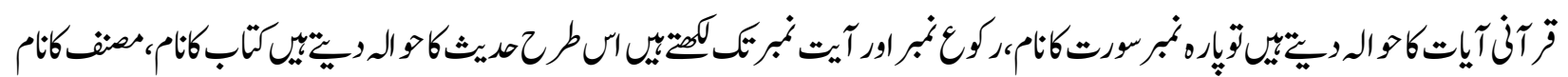

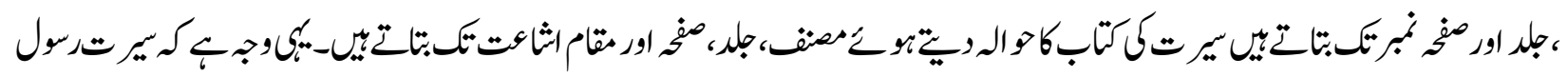

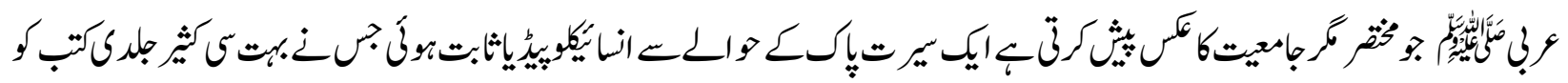

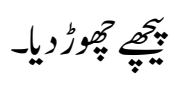

论败猔 